\title{
Effect of errors in genetic and environmental variances on the BLUP estimates of sire breeding values
}

\author{
A. Nardone and A. Valentini
}

Universita degli Studi della Tuscia, Istituto di Zootecnia, via S. Camillo de Lellis, 01100 Viterbo, Italy

(received 8 June 1989, accepted 13 September 1989)

Summary - The BLUP method for the estimation of breeding values requires the knowledge of the ratio of the residual over the genetic variance or of the heritability value $\left(h^{2}\right)$. The bias in the breeding value estimates caused by a wrong choice of $h^{2}$ has been examined by: (a) analysis of 11 populations simulated by varying the $h^{2}$ value of the trait and the offspring size of each sire $(n)$; (b) analysis of the weaning weights of 2055 Angus beef calves ( 725 dams bred to 89 sires). The breeding value estimates were found to be different depending on the $h^{2}$ value chosen. This error causes rank changes between sires and, consequently, a possible wrong choice of the subjects to be selected. For a $40 \%$ error in $h^{2}$ and $5<n<60$, we found that the \% bias : $26.2+47.9 / n-27.9 h^{2}$. When the data structure makes a serious bias likely to occur in the breeding value estimates, it is recommended to use a method for the variance components estimation, even if this is more time consuming from a computing point of view.

sire evaluation - mixed model — BLUP — variance components - heritability

Résumé - Effet de l'erreur des variances génétiques et résiduelles sur l'évaluation des taureaux par la méthode BLUP. La méthode BLUP pour estimer des valeurs génétiques nécessite la connaissance du rapport entre les variances résiduelles et génétiques ou de la valeur de l'héritabilité $\left(\mathrm{h}^{2}\right)$. L'effet d'une erreur de $\mathrm{h}^{2}$ sur les valeurs génétiques estimées a été étudié : (a) par l'analyse de 11 populations simulées en faisant varier $l^{\prime} \mathrm{h}^{2}$ du caractère et le nombre de produits (n) de chaque taureau; (b) par l'analyse du poids au sevrage de 2055 veaux de la race à viande Angus (725 vaches accouplées à 89 taureaux). Les estimations de la valeur génétique ont varié en fonction de $\mathrm{l}^{\prime} \mathrm{h}^{2}$ choisi. L'erreur est telle qu'elle détermine des changements de rang de classement entre les taureaux et, pour conséquent, un choix erroné des sujets à sélectionner. Pour une erreur de $40 \%$ sur $h^{2}$ et avec $5<n<$ 60 , nous avons trouvé que le pourcentage du biais était égal à $26,2-47,9 / h-27,9 h^{2}$. Dans les cas où l'on pense que l'erreur due au choix d'une $\mathrm{h}^{2}$ erronée infiuence de façon significative l'estimation de la valeur génétique, des méthodes pour l'estimation des composantes de la variance sont recommandées bien qu'elles peuvent exiger d'importants moyens de calculs.

évaluation des taureaux - modèle mixte - BLUP — composantes de la variance - héritabilité 


\section{INTRODUCTION}

The knowledge of the ratio $(k)$ of the environmental over the genetic variance is needed for a correct application of the BLUP method (Henderson, 1973). Henderson (1975) considered the bias due to incorrect variances without giving details about the variables that influence it and the eventual rank exchange between the parents; this aspect is, of course, of great interest for genetic improvement.

Since the $k$ ratio is often computed from the available heritability estimates of the considered trait (by $k=\left(4 / h^{2}\right)-1$ ), the aim of this note is to estimate the effect of a wrong choice of $h^{2}$ on the breeding value estimates and their possible rank modifications. For this purpose we took in consideration the weaning weights of beef cattle, since the heritability estimates for this character are highly variable. For example, a large literature review of $h^{2}$ estimates for beef cattle weaning weights (1980 to 1989) shows heritabilities ranging from 0.11 (lowest; Bertrand et al., 1985) and 0.54 (highest; Barlow \& O'Neill, 1980). Even within the same breed (Angus), $h^{2}$ ranges from 0.16 (Wilson et al., 1986) to 0.46 (Knights et al., 1984).

\section{MATERIAL AND METHODS}

We first used data of beef cattle weaning weights from 11 simulated populations, then we applied the results to a real Angus cattle population, which was at our disposal (Valentini, 1988).

The simulations were performed in order to have populations with predetermined $h^{2}$ values and with sires having varying offspring sizes, in order to quantify the effect of these variables on the eventual bias of the breeding value estimates of the sires. In particular:

-6 populations with a fixed number of sires each (equal to 60) and a fixed number of calves per sire (equal to 20); $h^{2}$ assumed a value increasingly varying from 0.10 and 0.55 for each population;

-5 populations with a fixed number of sires each (again equal to 60) and offspring per sire varying from 5 to $60 ; h^{2}$ assumed a value increasingly varying from 0.12 and 0.50 for each population.

The sire breeding values and the errors were generated assuming a normal distribution, while the fixed factor levels were assigned to each observation according to the uniform distribution. The averages of these populations were similar to those found in the real Angus population.

For these simulated populations, we proceeded as follows :

(a) the breeding values and $k$ values were computed by the EM algorithm (Dempster et al., 1984) applied on the REML method (Harville, 1977);

b) $k$ was arbitrarily biased by $+40 \%$ and the breeding values were estimated by BLUP;

c) the difference between the breeding value estimates was related by multiple regression to the REML heritability estimate and to the offspring size of each sire.

The Angus cattle population was made up of 2055 calves from 89 sires and 725 cows, belonging to a range herd in Hawaii Island (Hawaii, USA), studied over the period 1967-1987*. The weaning weights of the 2055 calves were adjusted to 205 days. On this real population, the breeding values of the sires were computed by a BLUP sire model using 3 different values for $h^{2}: 0.16$ and 0.46 (corresponding to the extremes found in the cited literature) and 0.22 (corresponding to the value computed by the EM-REML method on the same population, using a model considering the usual fixed factors; Valentini, 1988).

The model employed both for the Angus and the 11 simulated populations was simplified by only considering 1 fixed factor (the calf's sex) and 1 random factor (the sire), since for our

\# The authors whish to thank Prof. C.W. Weems, Chairman of the Department of Animal Science, University of Hawaii, USA, for kindly permitting the use of these data. 
study it was sufficient to have only 1 fixed factor in order to deal with a Heisenhart model III.

\section{RESULTS AND DISCUSSION}

On our simulated populations, we obtained the following prediction equation relating the percentage of the differences in the breeding value estimates (bias\%) obtained by using the REML $h^{2}$ estimate and the value biased by $40 \%$ with the sire offspring size $(n)$ and with the REML heritability estimate :

$$
\text { bias } \%=26.2+47.9 / n-27.9 h^{2}
$$

The $R^{2}$ of the model was 0.82 and the standard error of the estimated bias was 3.3. From eq. (1) it was found that:

(i) The percentage of bias is the same for sires with equal offspring size; therefore the absolute value of the bias increases as the breeding value differs from zero, which means that the bias is higher for the subjects that should be selected.

(ii) The bias is inversely proportional to the parent offspring size. Therefore 2 sires with different offspring sizes will have a different bias as a percentage. The difference between the 2 biases can be such that the 2 sires can reverse their rank.

We then tested these findings on the real Angus population referred to above. In this population the breeding value estimates of the 89 sires were found to be different depending on the $h^{2}$ chosen (Fig. 1). The absolute mean values, obtained with $h^{2}$ equal to 0.46 and 0.16 , differed from that obtained with $h^{2}=0.22$ by $1.86 \mathrm{~kg}$ $(42 \%)$ and $1.35 \mathrm{~kg} \mathrm{(30 \% )} \mathrm{respectively.}$ Moreover, if one considers the estimates of the best 15 sires, the mean error, as previously described, is almost twice that computed on all sires: 3.34 and $2.52 \mathrm{~kg}$ respectively for $h^{2}$ equal to 0.46 and 0.16 , as discussed above.

The different offspring per sire causes rank changes in the real population depending on the $h^{2}$ value employed for the breeding value estimation. In Fig. 2 the breeding values of the same 15 best sires are shown and the rank changes can be detected. Sire No. 12, estimated with $h^{2}=$ 0.46 , is better than sires Nos. $11,9,8$ and 6 , which, if estimated by $h^{2}=0.22$, are better than No. 12; this is also true for other subjects. In Table I the rank changes of all 89 sires are reported; 20 of the 89 sires, when estimated by $h^{2}=0.46$, changed their rank by 4 or more positions in com-

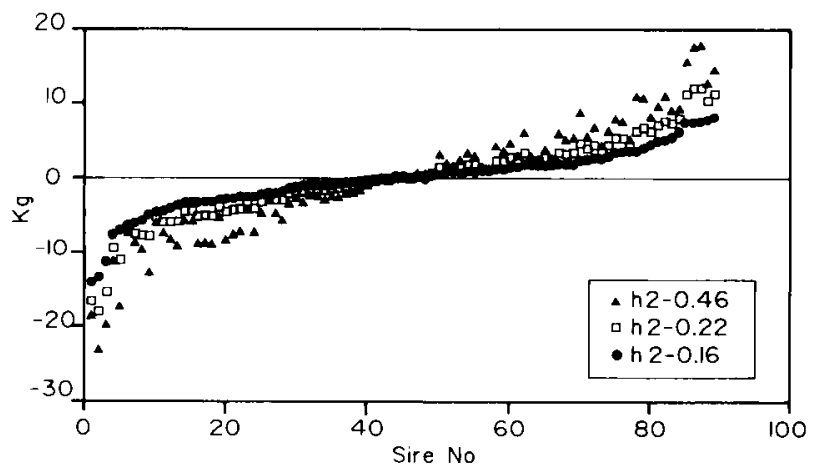

Fig. 1. Breeding value estimates of the Angus sires in ascending order. 


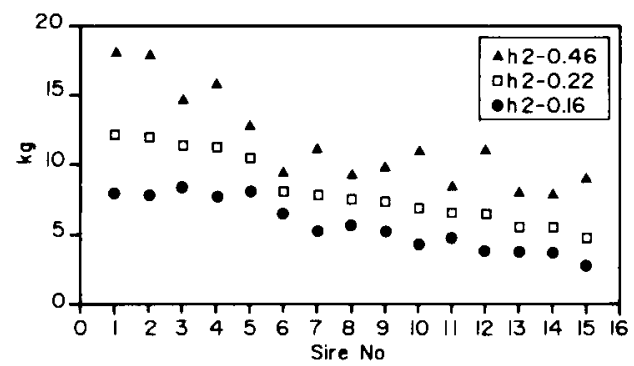

Fig. 2. Breeding value estimates of the best 15 Angus sires. the trait under selection is unknown and the data structure is likely to induce a serious bias, some of the future parents can be wrongly chosen, then a lower selection pressure will be applied and the genetic progress will be slowed down. In these cases (which could exist for some species (e.g. beef cattle, sheep, horses etc.) and for certain evironments the use of methods providing an estimation of the variance components, such as EM-REML, is justified, even if this is more time consuming from a computing point of view.

\section{REFERENCES}

Barlow R. \& O'Neill G.H. (1980) Performance of Hereford and crossbred Hereford cattle in the subtropics of New South Wales: genetic analyses of pre-weaning performance of first-cross calves. Austr. J. Agric. Res. 31, 417-427

Bertrand J.K., Berger P.J. \& Willham R.L. (1985) Sire $x$ environment interactions in beef cattle

Table I. Number of rank changes of the Angus sires when using $h^{2}$ values different from the true one $\left(h^{2} \approx 0.22\right)$.

\begin{tabular}{|c|c|c|c|}
\hline \multicolumn{2}{|c|}{$h^{2}=0.46$} & \multicolumn{2}{|c|}{$h^{2}=0.16$} \\
\hline $\begin{array}{l}\text { No. of } \\
\text { sires }\end{array}$ & $\begin{array}{c}\text { No. of } \\
\text { changed positions } \\
\text { per sire }\end{array}$ & $\begin{array}{l}\text { No. of } \\
\text { sires }\end{array}$ & $\begin{array}{l}\text { No. of } \\
\text { changed positions } \\
\text { per sire }\end{array}$ \\
\hline 21 & 0 & 22 & 0 \\
\hline 25 & 1 & 28 & 1 \\
\hline 11 & 2 & 22 & 2 \\
\hline 12 & 3 & 10 & 3 \\
\hline 8 & 4 & 3 & 4 \\
\hline 7 & 5 & 3 & 5 \\
\hline 0 & 6 & 0 & 6 \\
\hline 4 & 7 & 1 & 7 \\
\hline 1 & 8 & 0 & 8 \\
\hline
\end{tabular}


weaning weight field data. J. Anim. Sci. 60, 1396-1402

Dempster P.A., Patel M.C., Selwin R.M. \& Roth J.A. (1984) Statistical and computational aspects of mixed model analysis. Appl. Statist. 33, 203-214

Harville A.D. (1977) Maximum likelihood approaches to variance component estimation and to related problems. J. Am. Statist. Assoc. 72, 320-340

Henderson C.R. (1973) Sire evaluation and genetic trend. Proc. Animal Breeding and Genetics Symp. (in honor of Dr. Jay L. Lush) Am. Soc. Anim. Sci. and Am. Dairy Sci. Assoc. Champaign, IL, 10-41
Henderson C.R. (1975) Best linear unbiased estimation and prediction under a selection model. Biometrics 31, 423-449

Knights S.A., Backer R.L., Gianola D. \& Gibb J.B. (1984) Estimates of heritabilities and of genetic and phenotypic correlations among growth and reproductive traits in yearling Angus bulls. J. Anim. Sci. 58, 887-893

Valentini A. (1988) A new method to compute the variance components in beef cattle. Semin. Dept. Anim. Sci., University of Hawaii, HI, USA, 1-6

Wilson D.E., Berger P.J. \& Willham R.L. (1986) Estimates of beef growth trait variances and heritabilities determined from field records. $J$. Anim. Sci. 63, 386-394 